
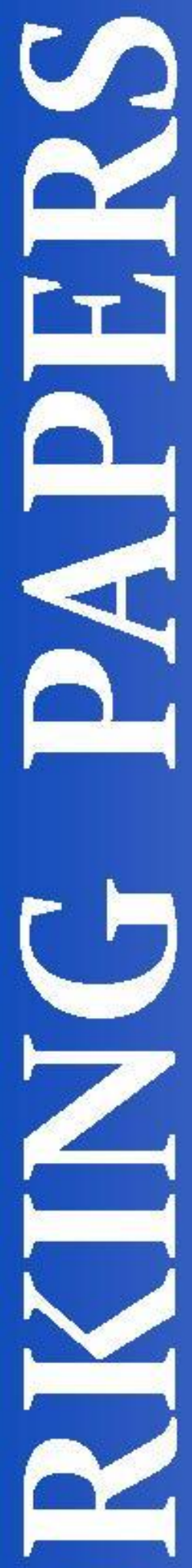

Inequality and unemployment patterns in Europe: Does integration lead to (real) convergence?

UNIVERSITAT JAUME•I
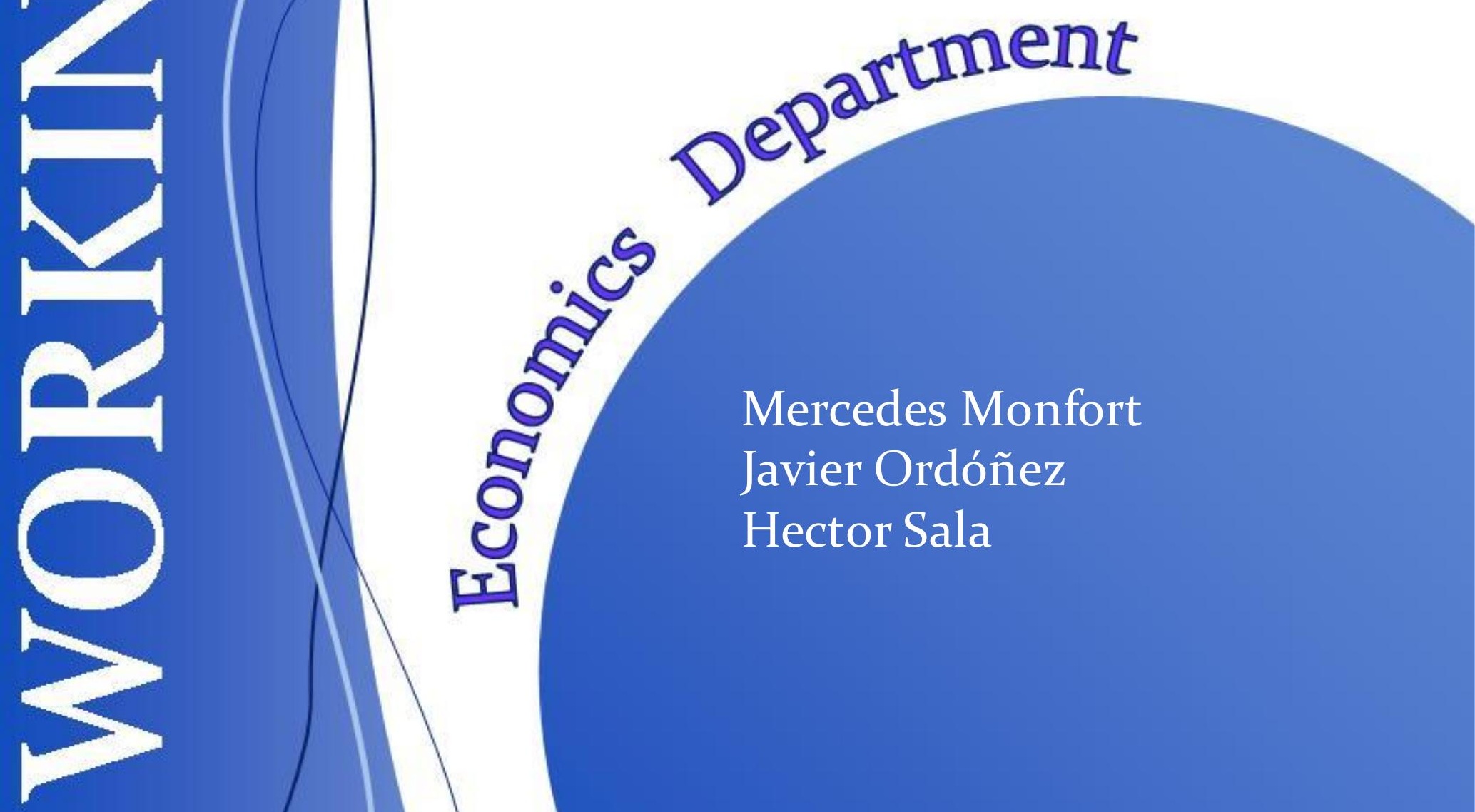

Castellón 2016 / 15 (Spain) 


\title{
Inequality and unemployment patterns in Europe: Does integration lead to (real) convergence?
}

\author{
Mercedes Monfort \\ University Jaume I \\ Department of Economics \& IEI \\ mmonfort@,uji.es.
}

\author{
Javier Ordóñez \\ UPAEP \& University Jaume I \\ Department of Economics \& IEI \\ jmonfort@eco.uji.es
}

\author{
Hector Sala \\ Universitat Autònoma de Barcelona \& IZA \\ Department of Economics \\ hector.sala@uab.es.
}

\begin{abstract}
$2016 / 15$
Abstract

The economic convergence criteria adopted in the Maastricht Treaty and the fiscal discipline of the Stability and Growth Pact enforced nominal convergence, leaving aside real convergence indicators. In this paper, we use cluster analysis to examine the convergence patterns of income inequality, absolute redistribution (a measure of governments' effectiveness in correcting for inequality) and unemployment. The expected outcome after years of economic integration was, ex-ante, convergence to a single cluster. Our results, however, uncover a variety of groups, implying that economic integration has not led to real economic convergence. Moreover, the existence of different patterns suggests: (i) that traditional classifications (Anglo-Saxon, Continental European, European Periphery, and Nordic models) remain broadly valid; (ii) that there is no unemployment-inequality trade-off to be exploited in terms of economic policy; and (iii) that the redistributive capacity of governments plays a pivotal role in coping with inequality without negative effects in terms of unemployment.
\end{abstract}

Keywords: Europe, convergence, clusters, unemployment, inequality, redistribution

JEL classification: C33, D63, F15 


\title{
Inequality and unemployment patterns in Europe: Does integration lead to (real) convergence?
}

\author{
Mercedes Monfort \\ Instituto de Economía Internacional and Universitat Jaume I \\ Javier Ordóñez \\ Instituto de Economía Internacional, Universitat Jaume I, and UPAEP \\ Hector Sala \\ Universitat Autònoma de Barcelona, and IZA
}

\begin{abstract}
The economic convergence criteria adopted in the Maastricht Treaty and the fiscal discipline of the Stability and Growth Pact enforced nominal convergence, leaving aside real convergence indicators. In this paper, we use cluster analysis to examine the convergence patterns of income inequality, absolute redistribution (a measure of governments' effectiveness in correcting for inequality) and unemployment. The expected outcome after years of economic integration was, ex-ante, convergence to a single cluster. Our results, however, uncover a variety of groups, implying that economic integration has not led to real economic convergence. Moreover, the existence of different patterns suggests: (i) that traditional classifications (Anglo-Saxon, Continental European, European Periphery, and Nordic models) remain broadly valid; (ii) that there is no unemployment-inequality trade-off to be exploited in terms of economic policy; and (iii) that the redistributive capacity of governments plays a pivotal role in coping with inequality without negative effects in terms of unemployment.
\end{abstract}

JEL: C33, D63, F15.

Keywords: Europe, convergence, clusters, unemployment, inequality, redistribution.

\footnotetext{
Acknowledgments

Javier Ordóñez is member of the INTECO research Group and gratefully acknowledges the support from the Generalitat Valenciana Project PROMETEOII/201/053 and AICO/2016/38, MINECO project ECO201458991-C3-2-R and the UJI project P1-1B2014-17. Hector Sala is grateful to the Spanish Ministry of Economy and Competitiveness for financial support through grant ECO2012-13081.
}

\section{Introduction}


Income inequality has been rising over the past three decades in the vast majority of OECD countries (OECD 2008, 2011, and 2015). These divergences have moved inequality to the top of the political agenda given the concern that such persistently unbalanced sharing of income and wealth will result in social resentment and political instability. In the European Union (EU), inequality has increased both between and within member states (European Commission, 2014), while unemployment is persistent and has recently reached historical maximum figures. This situation may threaten not only welfare and growth, but also social cohesion and public support for the integration process.

Most observers consider unemployment and inequality to be closely related. However, the recent economic crisis has shown that high unemployment increases inequality, with declining employment opportunities for the least skilled and a wider dispersion of earnings (OECD, 2015). In contrast, economic growth no longer seems to be associated with improved equality since strong growth may coexist with persistent labour underutilization and rising inequality (OECD, 2008).

At first glance, Figure 1 would seem to confirm a positive correlation between inequality and unemployment. The correlation coefficient between the two for the EU15 , however, only reaches 0.36 , reflecting the fact that unemployment has tended to rise continuously since the onset of the Great Financial Crisis (GFC) in 2007, while inequality jumped between 2006 and 2008, before subsequently stabilizing (with mild oscillations) at a higher plateau. This stabilization is associated with the effects of the redistributive policies undertaken in these years.

Figure 1. Gini index and unemployment rate. European Union-15.

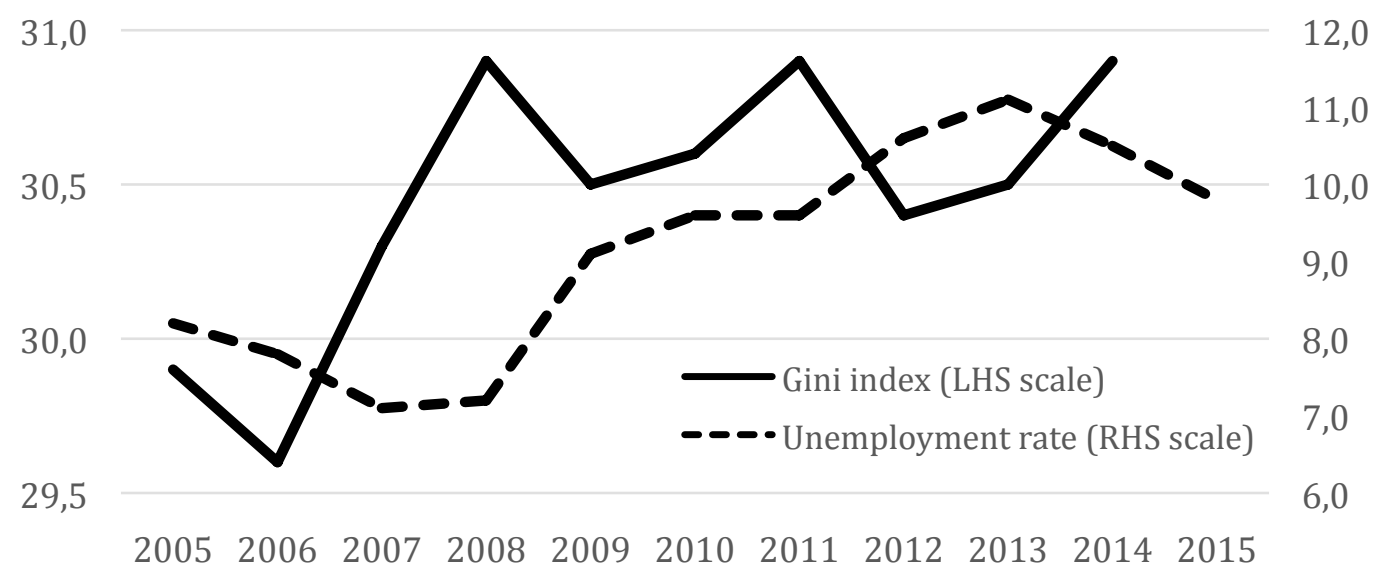

Source: Eurostat and Ameco Database. 
In parallel with these facts, the focus on the study of inequality in macroeconomics has shifted away from the causation analysis between inequality and long-term growth to the sources or causes of inequality (for example, financial liberalization, as in Buman and Lensick, 2016), and the consequences of inequality for the aggregate performance of the economy (Dabla-Norris et al., 2015). Yet the interaction with unemployment at a macroeconomic level has received less attention. ${ }^{1}$

Also, the role of globalization, or more specifically economic integration, has been scrutinized by the economic literature. As is usually the case, the findings are polarized and divergent. Whereas some authors conclude that globalization accentuates inequality (Firebaugh, 2003; Wade, 2004), others suggest that economic integration has played an important role in closing the inequality gap (Dollar and Kraay, 2002). More recently, institutional changes have been also proposed as an explanation for the rise in inequality. According to this view, the rise in top income shares is caused by the fall of top income marginal personal tax rates and financial deregulation (OECD, 2012).

Within the literature on the link between income distribution and economic integration, the studies analysing the effect of the European integration process on within-country and between-country inequality deserve special attention. The reduction of income inequality across the EU countries has long been a declared target of the EU. Consequently, regional policies at the EU level to promote the desired cohesion have been in place for many years. ${ }^{2}$ The key question to answer regarding the link between the European integration process and inequality patterns in Europe has been clearly set out by García-Peñalosa (2010, p. 277): "We can then ask whether such integration has had an effect on inequality, and to what extent it has resulted in a conflict between productive efficiency and distributive considerations". According to this author, it seems clear that one of the reasons why inequality may be observed among countries is the existence of different levels of technology.

Regarding the first element of this conflict, extant literature has shown that divergences in technology are indeed relevant among EU countries, and may even be at the root of the Euro crisis that erupted in 2008. Monfort et al. (2013) conduct a cluster analysis on labour productivity and show the absence of convergence to a single group,

\footnotetext{
${ }^{1}$ The literature dealing with the interaction between inequality and the labour market has mainly focused on earnings inequality, and the pressure brought by skill-biased technical change in terms of (un)employment and compensation, along the lines of seminal work by Katz and Murphy (1992).

${ }^{2}$ Bouvet (2010) shows that the Cohesion Funds are positively correlated with inequality, although this correlation should not be interpreted as causality. Also, this author also finds that the structural funds are weakly associated with lower inequality.
} 
and the existence of two clusters within the EU. In turn, Ordóñez et al. (2015) decompose the real unit labour costs into their various components (i.e., real wages, capital intensity, and technology) and reveal that the technological factor is the key to understanding the lack of real convergence within the Eurozone. These results would explain why, since the creation of the Eurozone, growing structural imbalances between member states have emerged without offsetting gains in productivity and economic growth. Hence, given the existence and persistence of competitiveness gaps, only two solutions exist. One, unfeasible in the short-run, is to embark on deep and comprehensive economic reforms to boost innovation and improve countries' technological status, thus enabling sufficiently strong catch-up processes. The second consists of austerity and internal devaluation processes, which have been implemented to close the gaps in competitiveness but with ensuing falling wages, growing unemployment and, consequently, a reduction in economic activity.

Amidst the economic turmoil left by the GFC, the legacy of these policies has been a severe rise in income inequality. However, have these policies disrupted a single converging path in social indicators? Were there in fact several clubs? Were these groups the same in terms of inequality and unemployment? Can we learn something from examining governments' redistributive capacity along the same lines? These questions will be addressed below, in an attempt to fill an important void in the literature concerning the progress of real convergence in terms of social indicators such as inequality and unemployment. As such, we respond to the call for further research issued in Goedemé and Collado (2016, p. 14), which "should focus on better understanding the driving forces of the dynamics of the EU-wide income distribution".

We thus propose to use cluster techniques to analyse the convergence or divergence of the EU countries in terms of inequality, unemployment, and absolute redistribution in an attempt to investigate whether these social indicators reproduce the cluster behaviour observed in more technology-related indicators (Monfort et al., 2013; Ordóñez et al., 2015). We propose to study inequality across countries for three reasons. First, between-country inequality shapes the dynamics of overall inequality in Europe, despite the fact that more than $60 \%$ of the inequality occurs within EU countries as opposed to between countries (Bouvet, 2010, p. 330). Second, most of the debate on the impact of the single market and common currency has focused on national economic conditions. Third, we seek to contribute to the existing literature on real divergences between the European countries by analysing the inequality as well as unemployment 
convergence patterns to gain further understanding of the conflict between efficiency and distributive considerations. The existence of multiple cluster convergence in inequality and unemployment would highlight the difficulties in achieving real convergence among EU countries, specifically among the Eurozone countries, and hence the difficulties in maintaining an incomplete economic integration process in both sets of real economic indicators: productivity/technology and inequality/unemployment.

To evaluate the existence of clusters, we follow the methodology proposed by Phillips and Sul $(2007,2009)$ in which different convergence paths can be distinguished among heterogeneous economies involved in a convergence process. This heterogeneity is modelled through a nonlinear time-varying factor model, which provides flexibility in studying idiosyncratic behaviours over time and across section.

Inequality is measured by the Gini index for household disposable income. Absolute income redistribution is the difference between the Gini index based on household disposable (post-tax and post-transfer) income and the Gini index based on household market (pre-tax and pre-transfers) income. The first one is usually referred to as Gini net, whereas the latter is called Gini market. Examining absolute redistribution allows us to investigate the cluster and time path behaviour of the reduction of marketincome inequality across the European countries due to taxes and transfers. The unemployment rate is defined as the number of unemployed persons as a percentage of the labour force.

Our results suggest that there is no evidence of real convergence across European countries in terms of income inequality, absolute distribution or unemployment. On the contrary, we see a variety of clusters emerge and Europe divided into groups with different characteristics. These clusters broadly reflect conventional wisdom on the idiosyncratic characteristics of the Anglo-Saxon (ANGLO), the Nordic, the European periphery (with the so-called PIIGS countries, Portugal, Ireland, Greece and Spain), and the European Continental (EUCON) "models". However, their composition varies depending on the indicator examined. Based on the evidence provided, we conclude that there is no exploitable trade-off between inequality and unemployment, and that absolute redistribution is a tool that should be further understood and exploited, at supranational European level, to cope with the unsatisfactory lack of social convergence.

The remainder of the paper is organized as follows. Section 2 discusses the reasons why a process of economic integration may not deliver the expected 
convergence in key real variables, such as unemployment and inequality. Section 3 presents the cluster methodology. Section 4 outlines the data. Section 5 shows the results for our three variables of interest. Section 6 concludes and draws some policy implications.

\section{Economic integration versus inequality and unemployment convergence}

We start this section by briefly referring to the outcomes of economic integration, including convergence. We then review three channels by which divergence may occur.

\subsection{European integration versus European convergence}

In a neoclassical world with rational agents, perfect information, perfect competition, and full mobility of production factors, economic integration should lead to economic convergence.

The European integration process has continuously evolved, trying to make progress in these dimensions by enhancing transparency (via well-defined regulations and institutional settings), competition (by broadening the market size), and factor mobility (through the elimination of all sorts of barriers). Milestone changes along the European integration path include the establishment of the European Monetary system in 1989, the Common Market in 1993, and the European and Monetary Union (EMU) in 1999.

All of these achievements have contributed to a very large and ever-growing degree of economic integration, as demonstrated by the rising rate of trade openness, and the progressive, though limited, synchronization of the business cycle within Europe (see Camacho et al., 2008, and de Haan et al., 2008).

Has this progress in economic integration translated into economic convergence? Certainly in nominal terms by means of the Treaty of Maastricht on European Union (signed in 1992), the Stability and Growth Pact (1998), and the Fiscal Stability Treaty (2012). The answer is not as clear, however, with respect to macroeconomic variables representative of real convergence. One example is per capita GDP, which in the periphery countries has tended to converge to the European average in good times, but tends to diverge during slumps.

Our interest, however, does not lie in the cyclical nature of these processes, but rather in the trend across business cycles, when structural convergence should be clearly perceived. Monfort et al. (2013) and Ordóñez et al. (2015) have shown, respectively, 
that convergence in labour productivity and in real unit labour costs has not been achieved. Therefore, before examining the case of social indicators such as unemployment and inequality, we need to determine the channels through which economic convergence may escape the process of economic integration.

\subsection{Potential channels for divergence}

Three potential channels for divergence are related to the impact of economic integration in terms of (i) economic governance, (ii) economic specialization, and (iii) government intervention.

The process of economic integration, particularly the adoption of a single currency in Europe, may have affected income distribution and unemployment through a number of channels. First, the loss of national stabilizing policy, such as the monetary policy and the exchange rate, as well as the fiscal-policy constraints imposed by the Stability and Growth Pact (SGP), can make it difficult to stabilize economic activity when savings and investment decisions are imperfectly correlated, and prices and wages are inflexible (Bertola, 2010). More specifically, one of the conditions set out in the Optimal Currency Area (OCA) theory, so that the benefits of forming part of a monetary union outweigh the costs, is the easing of both the goods and the labour markets regulations. According to this theory, the easing of both markets regulations should act as an alternative adjustment mechanism to compensate for the absence of stabilization policies. The lack of reforms in national markets and the varying scope of such reforms could explain these marked divergences between Eurozone countries. Furthermore, macroeconomic stabilization policies that transcend national boundaries might be appropriate for a subset of countries within the monetary zone sharing homogeneous economic cycles, but will not be for those with atypical cycles. When most labour market disruptions occur, whether at a regional or industry level, restrictions imposed by membership of the EMU on macroeconomic policies might be a source of, rather than a remedy for, economic fluctuations at a national level (Darvas et al., 2005). As pointed out by Barry and Begg (2003), the negative effects of the monetary union will be more pronounced in countries that have had to undergo the greatest changes in order to participate in the monetary union.

Secondly, with the EMU, not only do member states lose macroeconomic-policy independence, but new mechanisms that arise from the interaction of markets come into play at a microeconomic level. By promoting trade and factor mobility, market 
integration can affect the distribution of income, given that greater integration will lead to activity specialization and economic agglomeration (Brülhart and Torstensson, 1996; Krugman, 1991, 1991b), and in turn, differential growth across countries and regions. Furthermore, greater industrial specialization can also increase vulnerability to asymmetric shocks, thus intensifying inequalities between countries and regions (Midelfart, et al., 2003). Trade creation and diversion, as well as the mobility and the accumulation of production factors, influence the production patterns and revenues between countries and individuals that interact within a more integrated market. Similarly, in an integrated zone, markets react more quickly and more sharply to price differences, meaning that small-scale shocks can have major repercussions on the demand for labour, and by extension on the factors that impact on the wage gap between individuals with different sets of qualifications; a gap that largely explains income inequalities.

Lastly, the impact of economic integration on redistribution policies may be twofold. On the one hand, market deregulation and greater factor mobility could give rise to new sources of inequality requiring the implementation of new redistribution policies not included in the traditional welfare state, and that offset the negative effect of the risks associated with integration. Furthermore, economic integration also affects the feasibility of national redistribution policies. Broader markets improve efficiency because they provide individuals with a wider range of choices, but at the same time, they make it more difficult to implement redistribution policies. Depending on whether it is the demand or the supply shock that is dominant, economic integration may effectively increase or decrease the effectiveness of collective redistribution in deregulated markets (Agell, 2002).

\section{Methodology: the Phillips and Sul cluster analysis}

Multiple cluster convergence implies economic divergence. We therefore use cluster analysis to study whether the strengths of these divergence channels outweigh convergence drivers from the economic integration process. The panel data model by Phillips and Sul (2007) has been used to represent the behaviour of countries in transition, allowing for different convergence paths with heterogeneous individuals. Heterogeneity is formulated as a nonlinear time-varying factor model, which provides flexibility in idiosyncratic behaviour over time and across section. The model allows for idiosyncratic behaviour, and also retains some commonality across the panel, meaning 
that when the heterogeneous time-varying idiosyncratic components converge over time to a constant, panel convergence holds.

The starting point of the test is the following time-varying representation:

$$
X_{i t}=\delta_{i t} \mu_{t}
$$

where $\delta_{i t}$ is a time-varying factor-loading which captures convergence to a common factor, $\mu_{t}$. The simple econometric representation in (1) can be used to analyse convergence by testing whether the factor loadings $\delta_{i t}$ converge. Phillips and Sul (2007) proposed modelling the transition elements $\delta_{i t}$ through the construction of a relative measure of the transition coefficients:

$$
h_{i t}=\frac{X_{i t}}{\frac{1}{N} \sum_{i=1}^{N} X_{i t}}=\frac{\delta_{i t}}{\frac{1}{N} \sum_{i=1}^{N} \delta_{i t}}
$$

which measures the loading coefficient $\delta_{i t}$ in relation to the panel. The variable $h_{i t}$ is called the relative transition path, and traces out an individual trajectory for each $i$ relative to the panel average.

To formulate a null hypothesis of convergence, the authors proposed a semiparametric model for the time-varying behaviour of $\delta_{i t}$ as follows:

$$
\delta_{i t}=\delta_{i}+\sigma_{i} \xi_{i t} L(t)^{-1} t^{-\alpha}
$$

where $\delta_{i}$ is fixed, $\sigma_{i}>0, \xi_{i t}$ is i.i.d $(0,1)$ across $i$ but weakly dependent on $t^{3}$, and L $(t)$ is a slowly varying function for which $\mathrm{L}(t)$ tends to infinity as $\mathrm{t}$ also goes to infinity. Following Phillips and Sul (2007), the L(t) function is assumed to be $\log \mathrm{t}$; $\xi_{\text {it }}$ introduces time-varying and country-specific components into the model; and the size of $\alpha$ determines the behaviour (convergence or divergence) of $\delta_{i t}$. The null hypothesis of convergence can be written as:

$$
H_{0}: \delta_{i t}=\delta \text { and } \alpha \geq 0
$$

and the alternative:

$$
H_{A}: \delta_{i t}=\delta \text { for all } i \text { with } \alpha<0
$$

or

\footnotetext{
${ }^{3}$ These conditions imply that the stochastic component declines asymptotically so that the trend vanishes and each coefficient converges to $\delta_{i}$.
} 


$$
H_{A}: \delta_{i t} \neq \delta \text { for some } i \text { with } \alpha \geq 0 \text {, or } \alpha<0
$$

The alternative hypothesis includes divergence, as in (5) and (6), but can also consider club convergence. For example, if there are two convergent clubs, the alternative is:

$$
H_{A}: \delta_{i t} \rightarrow\left\{\begin{array}{l}
\delta_{1} \text { and } \alpha \geq 0, \text { if } i \in G_{1} \\
\delta_{2} \text { and } \alpha \geq 0, \text { if } i \in G_{2}
\end{array}\right.
$$

where $\mathrm{G}$ stands for a specific club.

Phillips and Sul (2007) show that these hypotheses can be statistically tested by means of the following ' $\log \mathrm{t}$ ' regression model:

$$
\log \left(H_{1} / H_{t}\right)-2 \log (\log (t))=a+b \log t+u_{t}
$$

for $\mathrm{t}=[\mathrm{rT}],[\mathrm{rT}]+1, \ldots, \mathrm{T}$ with some $\mathrm{r}>0$ and is $H_{1} / H_{t}$ the cross-sectional variance ratio.

The convergence patterns within groups (that is, the existence of club convergence and then clustering) can be examined using $\log t$ regressions. The so-called 'core group', $G_{k}$, is chosen by maximizing $t_{k}$ over $k$ individuals according to the criterion:

$$
k^{*}=\arg \max \left\{t_{k}\right\}, \text { subject to } \min \left\{t_{k}\right\}>-1.65
$$

The convergence approach by Phillips and Sul (2007) presents clear advantages. First, it is a test for relative convergence, as it measures convergence to some crosssectional average, in contrast to the concept of level convergence used by Bernard and Durlauf (1996). Second, this approach outperforms the standard panel unit root tests since in the latter case $X_{i t}-X_{j t}$ may retain nonstationary characteristics even though the convergence condition holds. In other words, panel unit root tests may classify the difference between gradually converging series as non-stationary. As a further problem, a mixture of stationary and non-stationary series in the panel may bias the results of unit root tests. Finally, these test results are not always particularly robust. This is in contrast to the Phillips and Sul (2007) test, which does not depend on any particular assumption concerning trend stationarity or stochastic non-stationarity of the variables to be tested. 


\section{Data and stylized facts}

Data on unemployment rates are taken from the OECD Main Economic Indicators Database and cover the period from 1960 to 2015 . We restrict the sample of countries to those for which inequality data is available.

Data on Gini coefficients are taken from the Standardized World Income Inequality Database (SWIID) developed by Solt $(2009,2014)$. The purpose of this database is to provide comparable Gini indices with the widest possible coverage across countries and over time. More precisely, long time series since the early 1970s are available for Belgium, Bulgaria, Denmark, France, Finland, Germany, Greece, Hungary, Ireland, Italy, the Netherlands, Norway, Portugal, Spain, Sweden, the United Kingdom and the United States. We analyse convergence in inequality for this relevant group of countries, for the period 1973-2012.

The SWIID contains Gini indices of net and market income inequality computed from a large set of inequality data sources. Gini net refers to the measure of income inequality once government intervention has taken place, while Gini market is a pre-tax, pre-transfer measure. The cluster analysis is carried out for the Gini net index and for the difference between the Gini net and the Gini market indices, the latter being a measure of absolute redistribution through the national tax system.

Table 1 shows the change in our three variables of interest between the early 1970s and today. Several salient facts are revealed. First, Europe has moved from a low unemployment regime (with rates below 3\%) to a high unemployment regime (with rates around $10 \%$ ). Second, this change is not reflected in net inequality, which has basically remained stable. Third, over the last four decades, the economies under study have succeeded in improving the effectiveness of public policy tools to combat inequality. Fourth, behaviour across economies is remarkably heterogeneous, and this is ultimately what makes our cluster analysis necessary.

Economies belonging to the ANGLO and EUCON groups have experienced small increases in unemployment, which is in stark contrast to some of the PIIGS countries (Portugal and, especially, Greece and Spain). Ireland (+8.5 percentage points), and France $(+7.6$ percentage points) lie in between. There is heterogeneity within the NORDIC group itself, with good performances in Norway and Sweden, but not in Denmark and Finland. 
Table 1. Unemployment rate (\%), Gini index, and absolute redistribution

\begin{tabular}{lcccccccc}
\hline & \multicolumn{2}{c}{$\begin{array}{c}\text { Unemployment } \\
\text { rate }\end{array}$} & & \multicolumn{2}{c}{ Inequality } & & \multicolumn{2}{c}{$\begin{array}{c}\text { Absolute } \\
\text { redistribution }\end{array}$} \\
\cline { 2 - 3 } \cline { 7 - 8 } \cline { 7 - 8 } Belgium & $\mathbf{1 9 7 3}$ & $\mathbf{2 0 1 5}$ & & $\mathbf{1 9 7 3}$ & $\mathbf{2 0 1 2}$ & & $\mathbf{1 9 7 5}$ & $\mathbf{2 0 1 2}$ \\
Denmark & 2.2 & 8.3 & & 26.0 & 24.9 & & 20.5 & 20.5 \\
Finland & 2.2 & 6.0 & & 27.4 & 25.9 & & 21.5 & 24.2 \\
France & 1.0 & 9.5 & & 23.4 & 25.7 & & 16.4 & 23.4 \\
Germany & 2.4 & 10.5 & & 33.0 & 30.7 & & 10.7 & 20.1 \\
Greece & 0.7 & 4.8 & & 27.2 & 28.7 & & 11.0 & 19.5 \\
Ireland & 2.6 & 25.1 & & 36.5 & 33.7 & & 14.0 & 19.4 \\
Italy & 1.6 & 9.4 & & 35.8 & 28.6 & & 7.8 & 26.1 \\
Netherlands & 2.5 & 11.9 & & 37.1 & 32.5 & & 13.9 & 17.2 \\
Norway & 2.0 & 6.9 & & 25.4 & 25.7 & & 20.8 & 20.9 \\
Portugal & 6.2 & 3.7 & & 25.7 & 24.3 & & 15.4 & 18.4 \\
Spain & 5.9 & 12.6 & & 22.8 & 33.6 & & 17.3 & 22.5 \\
Sweden & 2.6 & 22.3 & & 32.7 & 35.2 & & 8.6 & 18.0 \\
UK & 2.6 & 7.4 & & 25.4 & 24.0 & & 18.6 & 25.2 \\
US & 2.2 & 5.2 & & 26.9 & 34.9 & & 10.8 & 14.6 \\
& 4.9 & 5.3 & & 31.2 & 36.1 & & 10.2 & 17.3 \\
Average & $\mathbf{2 . 8}$ & $\mathbf{9 . 9}$ & & $\mathbf{2 9 . 1}$ & $\mathbf{2 9 . 6}$ & & $\mathbf{1 4 . 5}$ & $\mathbf{2 0 . 5}$ \\
\hline
\end{tabular}

Regarding net inequality, Portugal shows the largest increase, followed by the ANGLO economies. Most countries have succeeded in keeping the Gini net index at least at its original level, if not below. This is due to substantial improvements in the use of taxes and transfers to counteract income inequality. It is important to note that Belgium, Denmark, the Netherlands, and Norway are the economies that show the least progress in absolute redistribution, but this is because they have seen only very slight increases in Gini. At the other extreme, Portugal and the UK have registered little progress in absolute redistribution, in spite of rising inequality. This is in contrast to the US, where the government's redistributive capacity has improved and thus mitigated the significant increase in market inequality.

\section{Results}

The main results from the cluster analysis are summarized in Tables 1 to $3{ }^{4}$ The accompanying Figures 1 to 3 show the transition paths corresponding to the estimated clusters. To interpret these graphs, consider Figure 2, for example, where the time path behaviour of inequality is shown for a specific cluster relative to the whole panel, with the whole panel average represented by the unit horizontal line. A decrease in the

\footnotetext{
${ }^{4}$ Tables 1 to 3 summarize the information presented in Tables A1 to A8 in the Appendix. More precisely, Tables A1 to Table A3 show the cluster results for the unemployment rates; Tables A4 to A6 show the cluster results for the Gini net index; while Tables A7 to A8 present the cluster analysis for absolute redistribution.
} 
transition path of inequality for a given cluster cannot be interpreted as a decrease in absolute inequality, but rather as a decrease in inequality relative to the behaviour of the whole panel. Therefore, these graphs are useful way to gauge the degree of convergence among clusters and to determine when, and for how long, this convergence takes place.

\subsection{Unemployment}

Table 2 presents the clusters identified for unemployment rates in a sample between 1960 and 2015 while Figure 2 shows the transition paths corresponding to each cluster.

Table 2. Unemployment (1960-2015).

\begin{tabular}{|c|c|c|c|c|}
\hline Cluster 1 & Cluster 2 & Cluster 3 & Cluster 4 & Cluster 5 \\
\hline $\begin{array}{l}\text { Denmark, } \\
\text { Netherlands, } \\
\text { UK, and US }\end{array}$ & $\begin{array}{c}\text { Germany and } \\
\text { Norway }\end{array}$ & $\begin{array}{l}\text { Belgium, } \\
\text { Finland, and } \\
\text { Sweden }\end{array}$ & $\begin{array}{l}\text { Greece and } \\
\text { Spain }\end{array}$ & $\begin{array}{c}\text { France, } \\
\text { Ireland, Italy, } \\
\text { and Portugal }\end{array}$ \\
\hline
\end{tabular}

Note: Detailed information on the cluster analysis is provided in Tables A1-A3 in the Appendix.

When looking at the transition paths followed by the clusters in terms of unemployment, two features are immediately notable: first, the large differences among them, both at the beginning and end of the sample period; and, second, the similar relative positions they occupy half a century later. More precisely, Cluster 4 (Greece and Spain) and Cluster 5 (Ireland, Italy, Portugal and France) were above the average in the 1960s, and still are in 2014. In turn, Cluster 2 contains the best performers at the two extremes of the sample (Germany and Norway), while the changes taking place in the economies clustered in groups 1 (Denmark, the Netherlands, the UK and the US) and 3 (Belgium, Finland, and Sweden) lie mainly between these two groups, with average unemployment rates for these clusters below the general average represented by 1 .

The transition path of Cluster 1 shows peaks in the aftermath of the oil price shocks in the 1970 s, probably reflecting the relatively greater sensitivity to shocks in these economies (especially the UK and the US). The path then moves continuously downward until it virtually converges with the situation of Cluster 2. Therefore, in terms of unemployment, the Anglo-Saxon model of the UK and US, the flexicurity model of Denmark, and the emphasis on part-time jobs in the Netherlands (plus other forms of non-regular employment used to overcome the 'Dutch disease' and regain 
competitiveness), have contributed to the positive labour market performance of these economies, which have converged the best performers.

The worst time for the transition path of Cluster 3 coincides with the major economic crisis experienced in the early 1990s by the so-called twin economies, Finland and Sweden. Nevertheless, after some years without further deterioration, they have succeeded in re-establishing an average cluster unemployment rate below the general average, as it was up until 1990 and before.

\section{Figure 2. Transition paths for the unemployment rate}

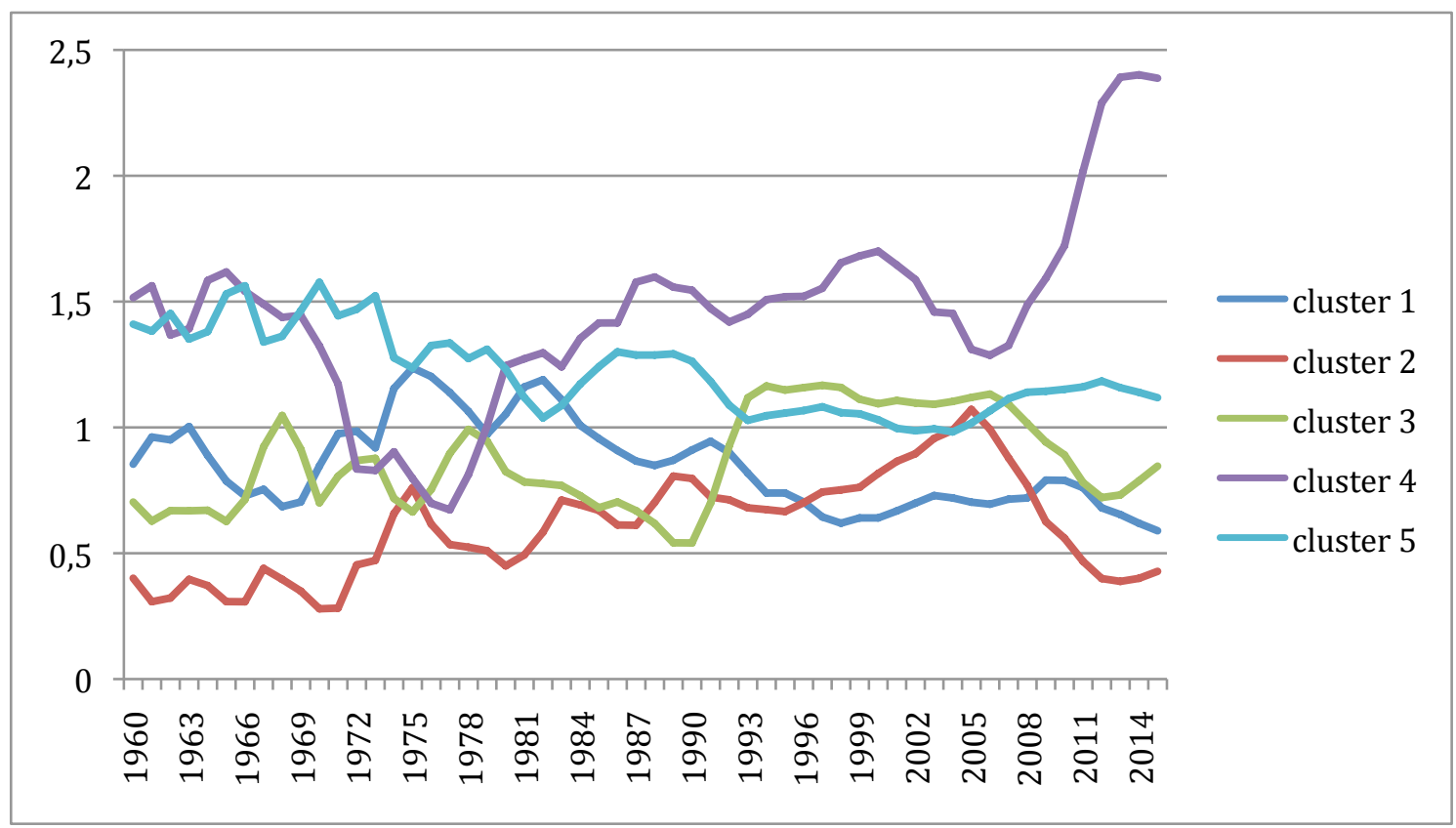

Cluster 5 depicts a story of relative success. Countries belonging to this group had an average unemployment rate 50\% above the general cluster average in the 1960s. By the 1990s, they had converged to this average and since then only the GFC has caused a (mild) deviation. This is clearly in contrast to the worrisome transition path followed by Cluster 4. Although Greece and Spain were quicker to converge in the late 1960s and early 1970s, since then they have experienced three periods of significant divergence from the others. One such divergence occurred in the aftermath of the oil price shocks (between the late 1970s and late 1980s); another during the transition from the Common Market to the EMU; and a third, and devastating one, brought about by the GFC and the subsequent systematic implementation of austerity measures and a structural reform agenda. This has caused the transition path of Cluster 4 to diverge massively, and 
created a situation fully at odds with the principles (and expectations) under which the idea of a single Europe was originally developed.

Therefore, although recent analyses of the GFC tend to place all the Southern European periphery countries in the same category, our results point to different conditions (given that these countries are grouped in different clusters) and also a different evolution (given that the two clusters have followed markedly different trajectories).

In showing a wide variety of labour market performances, our findings call for specific attention to be paid to each group of economies. If several clusters exist and, furthermore, if these clusters evolve in different directions, common policy recipes may not be enough to ensure the long-awaited real convergence within Europe. These specificities should be taken into account when determining the type of policy to be implemented. If not, the strictness or degree to which polices are implemented should at least be weighted by the circumstances and the consequent needs of each economy or group of economies. Failure to take this into consideration could lead to asymmetric effects and further exacerbation of social differences within Europe.

\subsection{Inequality}

Table 3 presents the clusters identified for inequality before public intervention (pre-tax, pre-transfers) in a sample between 1973 and 2012 while Figure 3 shows the transition paths corresponding to each cluster.

Regarding net inequality, Cluster 1 (with the UK and the US) and Cluster 4 (with the PIIGS countries) are characterized by inequality levels above the average. Cluster 1 started diverging from the average in the late 1970s and has experienced an average inequality of around $20 \%$ above the aggregate cluster average ever since. The moment of departure coincides with the aftermath of the oil price shocks and the political change brought by Margaret Thatcher and Ronald Reagan. The subsequent stabilization at high inequality levels is one of the salient characteristics that has since defined the AngloSaxon model (low unemployment rates being another). 
Table 3. Inequality (1973-2012).

\begin{tabular}{|c|c|c|c|c|}
\hline Cluster 1 & Cluster 2 & Cluster 3 & Cluster 4 & Cluster 5 \\
\hline UK and US & $\begin{array}{c}\text { France, } \\
\text { Germany, } \\
\text { and Finland }\end{array}$ & $\begin{array}{l}\text { Belgium, } \\
\text { Netherlands, } \\
\text { Denmark, } \\
\text { Norway, and } \\
\text { Sweden }\end{array}$ & $\begin{array}{c}\text { Greece, } \\
\text { Ireland, Italy, } \\
\text { Portugal, and } \\
\text { Spain }\end{array}$ & $\begin{array}{c}\text { Bulgaria and } \\
\text { Hungary }\end{array}$ \\
\hline
\end{tabular}

Note: Detailed information on the cluster analysis is provided in Tables A4-A6 in the Appendix.

\section{Figure 3. Transition paths for inequality}

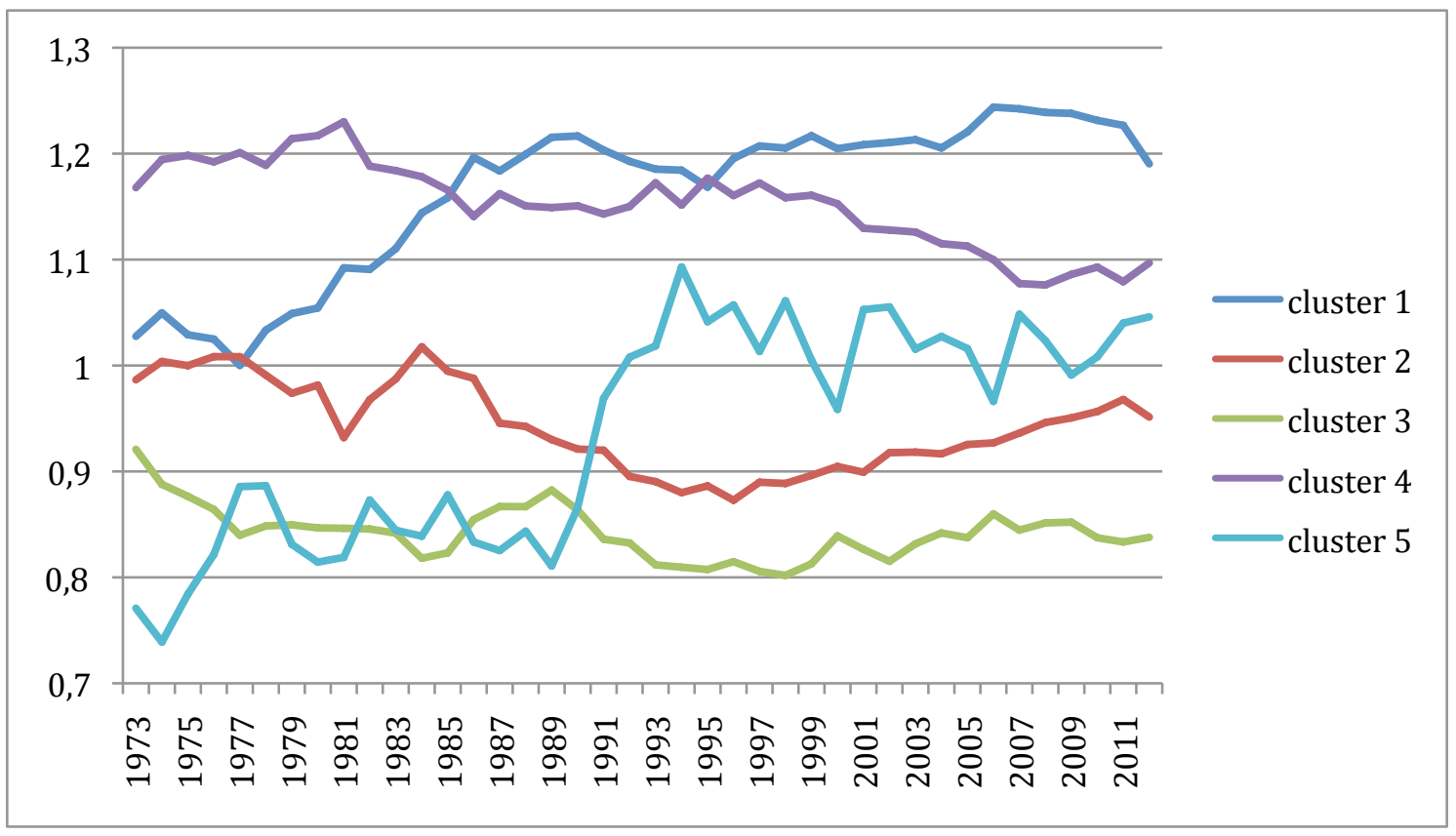

In contrast, the transition path of Cluster 4 (Greece, Ireland, Italy, Portugal, and Spain) starts off with a value $20 \%$ above the overall average of all clusters, and then follows a downward trend between 1980 and the years of the GFC, before stabilizing at just $10 \%$ above this average. This implies that the PIIGS countries have tended to converge in income distribution, driven by the consolidation of the welfare state in countries that in the mid-1970s moved from dictatorships to democracy (Greece, 1974; Portugal, 1975; and Spain, 1977), and subsequently joined the European Economic Community (in the 1980s).

The transition paths for Cluster 2 (with France, Germany, and Finland) and Cluster 3 (with Belgium, the Netherlands, Denmark, Norway and Sweden) display 
similar trajectories. They are always below the average, but diverge from the overall mean of all clusters between the 1960s and the 1990s, and then converge from the late 1990s onwards. However, although their behaviour is similar, Cluster 3 has always maintained a better situation than Cluster 4, and remained farther below the average.

This evolution confirms the traditional classification of countries, in terms of inequality, based on the 'harsh' Anglo-Saxon model; the 'caring' European model, here represented by the EUCON and NORDIC countries; the European periphery, struggling to converge; and the newcomer Eastern countries, stabilizing after the structural shock associated with the fall of the Wall.

\subsection{Absolute redistribution}

Table 4 presents the clusters identified for the degree of absolute redistribution achieved through government intervention, in the same sample as the post-tax/post-transfers inequality. ${ }^{5}$ As noted above, absolute income redistribution measures the number of points increase in the Gini index that government intervention succeeds in preventing through taxes and transfers. The first cluster (with the UK and the US), is characterized by a relatively small amount of overall taxes. The second cluster (Denmark, Ireland and Sweden) is made up of countries with relatively high gross tax payable and a lower share of employer and employee national insurance contributions to total tax. Ireland and Sweden also have a generous tax allowance and tax credit benefit systems. The third cluster is composed of countries with a higher share of employer and employee contributions in total taxes, and lower tax allowance and tax credit benefits than the previous group. With the exception of the Netherlands, these countries also have one of the highest shares of pension transfers over total benefits within the sample of analysed countries. Finally, the last group comprises countries with relatively high levels of direct taxation, but only moderate or low levels of income redistribution. In this regard, our results reflect the structure and complexity of the tax system as analysed in Avram et al. (2014) regarding income distribution.

\footnotetext{
${ }^{5}$ Lack of data prevent us from including Bulgaria and Hungary in the cluster analysis of absolute redistribution. Furthermore, the 1974 data for Gini market in Spain is not available and so the sample now starts in 1975.
} 
Table 4. Absolute redistribution (1975-2012).

\begin{tabular}{|c|c|c|c|}
\hline Cluster 1 & Cluster 2 & Cluster 3 & Cluster 4 \\
\hline UK and US & $\begin{array}{l}\text { Denmark, } \\
\text { Ireland, and } \\
\text { Sweden }\end{array}$ & $\begin{array}{l}\text { Belgium, } \\
\text { Finland, } \\
\text { France, } \\
\text { Germany, } \\
\text { Netherlands, } \\
\text { and Norway }\end{array}$ & $\begin{array}{c}\text { Greece, Italy, } \\
\text { Portugal, and } \\
\text { Spain }\end{array}$ \\
\hline
\end{tabular}

Note: Detailed information on the cluster analysis is provided in Tables A7-A8 in the Appendix.

Figure 4 shows the transition paths corresponding to each cluster. Divergence from the overall average, above the horizontal unit line, reflects above-average effectiveness in correcting for income inequality, whereas divergence below the unit line reflects below-average performance in terms of the cluster's capacity to correct for income inequality.

\section{Figure 4. Transition paths for absolute redistribution}

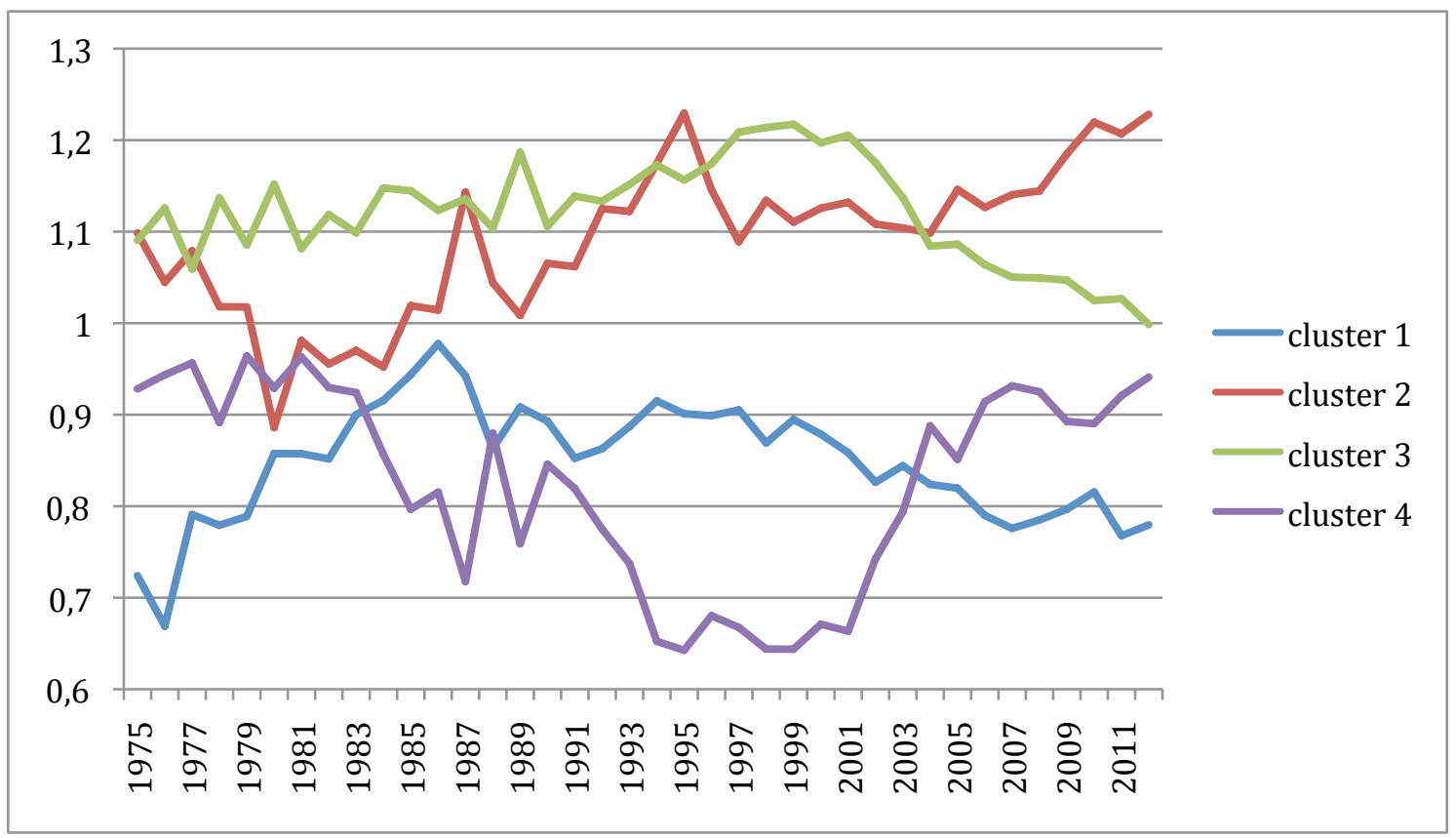


The transition path of Cluster 1 (UK and US) shows a clear divergent pattern. Public policies in these economies attained maximum effectiveness relative to the average of all clusters in the mid-1980s; since then, however, they have become progressively less successful, with a divergence of as much as $20 \%$ in recent times compared to the aggregate average. Cluster 2 (Denmark, Ireland, and Sweden) presents sharply contrasting behaviour. Since 1980, when absolute redistribution in this cluster was clearly inferior to the overall average ( $10 \%$ below $)$, it has grown to a point where it is $20 \%$ more effective.

Cluster 3 (Belgium, Finland, France, Germany, the Netherlands, and Norway) and Cluster 4 (Greece, Italy, Portugal, and Spain) have also followed opposite trajectories. Cluster 3 groups economies with above-average capacity to redistribute income (around $10 \%$ in the $1970 \mathrm{~s}$ and $1980 \mathrm{~s}$, and even $20 \%$ above in the late $1990 \mathrm{~s}$ ); however, in the $2000 \mathrm{~s}$ it has deteriorated and converged to the overall average of all clusters. In turn, Cluster 4 groups economies with below-average capacity to redistribute income (less than $10 \%$ in the $1970 \mathrm{~s}$ ), before progressively diverging from the average until the mid1990s. In the 2000s it has progressively converged to the overall average, although the effects of austerity measures (which started in the second half of 2010 and are not yet reflected in the data) will probably be devastating in terms of the absolute redistribution capacity of Cluster 4.

Our analysis indicates that the ANGLO group seems to have a structural problem regarding inequality, at least in relative terms, while the case of the PIIGS countries is more conjunctural. Given the present situation in terms of unemployment (recall the huge divergence of Cluster 4, depicted in Figure 1) this conjunctural issue is at risk of becoming a structural one. This situation calls for better coordination between labour market and income distribution policies in Southern Europe.

\section{Concluding remarks}

According to our results, the economic integration process in Europe has not led to real convergence in unemployment and inequality among the European countries. The expected outcome after years of ever-closer economic integration was, ex-ante, convergence to a single cluster in major economic dimensions such as those related to economic efficiency (labour productivity), wealth (per capita GDP), and social variables (unemployment, income inequality). However, the existence of cluster heterogeneity in the former (as shown by Monfort et al., 2013) and the latter (as shown in this study) 
casts serious doubts on the extent of real convergence. In addition, there seem to be prevalent differences in the effectiveness of public policies to combat inequality.

Our analysis, therefore, has two far-reaching implications. The first is that the promotion of cohesion, one of the declared objectives of the European Union, has largely failed. The second is that the sustainability of an integrated economic area with diverging countries is clearly doubtful (quite apart from the well-known tensions created by the Eurozone and the sovereign-debt crisis).

In addition, it has become clear that the nominal convergence criteria adopted in the Maastricht Treaty, and the fiscal discipline imposed by the Stability and Growth Pact, have had limited success in reducing disparities in unemployment and income inequality. Although they have been significant in helping to achieve convergence within some groups of countries, we should not overlook the fact that these economies were already structurally similar. In any case, in spite of many years of economic integration, the traditional north-south divide, the so-called two-speed Europe, is still present along with the east-west divide that emerged in Europe as the new members joined the club. On top of this, the Euro crisis has played a part in exacerbating divergences in unemployment and inequality, at the same time as the burden of the adjustment is being borne by the weakest economies. The additional problems wrought by the GFC, however, should not divert attention from the crucial message of this analysis: the most ambitious, rigorous and consolidated process of economic integration in modern history has not been successful in generating real economic convergence.

Our findings do not paint a clear picture in terms of an unemployment-inequality trade-off. In terms of unemployment, the UK and the US are clustered with Denmark and the Netherlands, two countries with low inequality and high absolute redistribution. Likewise, Germany clearly outperforms France in terms of unemployment, even though both countries are in the same clusters with respect to inequality and absolute redistribution. Moreover, the PIIGS countries are divided into two clusters in terms of unemployment (with Greece and Spain displaying extreme behaviour), despite the fact that they form a homogeneous group with respect to income inequality and (with the exception of Ireland) absolute redistribution.

Although there has been some support in the literature for the existence of a tradeoff between unemployment and wage inequality, which would be fostered by globalization and skill-biased technical change, our results uncover a much complex situation. In fact, Table 1 shows that net inequality has remained stable since the 1970s, 
while unemployment has more than tripled on average. By showing the country averages of the unemployment rates and Gini coefficients, Figure 5 illustrates the wide range of situations regarding inequality, and the relatively similar conditions regarding unemployment (with the exception of Spain).

Taking an average perspective, there is no trade-off, but rather a mild positive relationship and a vertical line of groups. This, together with the fact that the evolution of unemployment and inequality reveals clusters with a variety of country-compositions and different trajectories, suggests that there is no single policy recipe that could be recommended across the board. Therefore, it does not seem reasonable, for example, to claim that labour market deregulation policies will tend to reduce unemployment at the cost of increasing inequalities; or to claim that increasing wages (by encouraging the socalled wage-pressure factors and unfriendly labour market institutions) will reduce income inequality at the expense of unemployment.

\section{Figure 5. Unemployment-inequality patterns (1973-2012)}

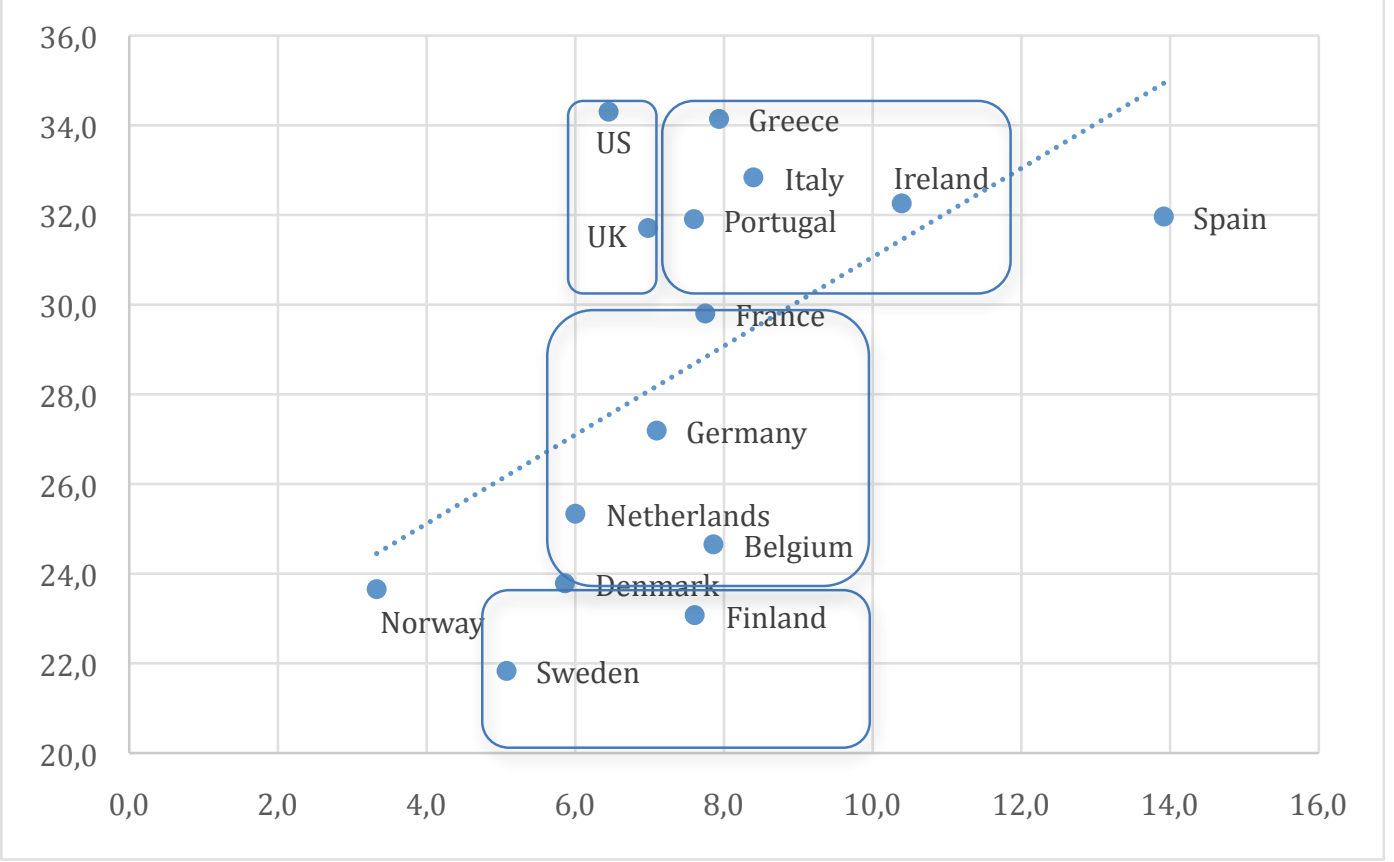

Note: The vertical axis depicts the average Gini net value in 1973-2012; the horizontal axis shows the average unemployment rate in 1973-2012.

In contrast to these standard generic policies, our view is that the absolute redistribution attained through public action plays a pivotal role that should be further understood, and exploited in terms of economic policy. This claim goes far beyond the austerity-versus-growth debate. Irrespective of whether there is an expansionary or a 
contractionary fiscal policy, it is the structure of taxes and transfers, and their consequences for some specific groups that should be carefully analysed in terms of their macroeconomic consequences. In this respect, even though Goedemé and Collado (2016) provide an optimistic appraisal for people living on the lowest incomes, they also acknowledge that there are still significant caveats.

To conclude, the fact that most Nordic economies appear in the "healthiest" clusters (number 5 regarding inequality, and number 2 regarding absolute redistribution), and Germany and Norway are in the best one in terms of unemployment, should act as a warning to European authorities that pursuing structural reforms and generic deregulation policies may bring Europe closer to the Anglo-Saxon model. Our study calls for action in the opposite direction, pointing to Germany (regarding the labour market performance) and Scandinavia (regarding inequality) as models to follow.

\section{References}

Agell, J. (2002) 'On the Determinants of Labour Market Institutions: Rent Seeking vs. Social Insurance'. German Economic Review, Vol. 4, pp. 29-48.

Avram, S., H. Levy and H. Sutherland (2014) 'Income Distribution in the European Union'. IZA Journal of European Labor Studies, pp. 3-22.

Barry, F. and Begg, I. (2003) 'EMU and Cohesion: Introduction'. Journal of Common Market Studies, Vol. 41, pp. 781-796.

Bernard, A.B. and Durlauf, S.N. (1995) 'Convergence in International Outputs'. Journal of Applied Econometrics, Vol. 10, pp. 97-108.

Bertola, G. (2010) 'Inequality, integration, and policy: issues and evidence from EMU'. Journal of Economic Inequality, Vol. 8, pp. 345-365.

Bouvet, F. (2010) 'EMU and the Dynamics of Regional Per Capita Income Inequality in Europe'. Journal of Economic Inequality, Vol. 8, pp. 323-344.

Bumann, S. and Lensink, R. (2016) "Capital account liberalization and income inequality". Journal of International Money and Finance, Vol. 61, pp. 143-162.

Brülhart, M. and Tortensson, J. (1996) 'Regional Integration, Scale Economies, and Industry Location in the European Union'. CEPR Discussion Paper Series, 1435.

Camacho, M. Pérez-Quirós, G. and Saiz, L. (2008) 'Do European business cycles look like one?'. Journal of Economic Dynamics and Control, Vol. 29, pp. 3177-3185.

Dabla-Norris, E.; Kochhar, K.; Ricka, F.; Suphaphiphat, N.; Tsounta, E. 2015. Causes and consequences of income inequality: A global perspective, IMF Staff Discussion Note 15/13.

Darvas, Z., Rose, A.K. and Szapáry, G. (2005) 'Fiscal divergence and Business cycle synchronization: irresponsibility is idiosyncratic'. In: Frankel, J. and Pissarides, C. (eds.) NBER International Seminar on Macroeconomics, MIT, Cambridge. 
De Haan, J., Inklaar, R. and Jong-A-Pin, R. (2008) 'Will business cycles in the euro area converge? A critical survey of empirical research'. Journal of Economic Surveys, Vol. 22, pp. 234-273.

Dollar, D. and Kraay, A. (2002) 'Spreading the wealth'. Foreign Affairs, Vol. 81, pp. 120-133.

European Commission (2014): An ever closer union among the peoples of Europe? Rising inequalities in the EU and their social, economic and political impacts, European Commission, Directorate-General for Research and Innovation.

Firebaugh, G. (2003): The New Geography of Global Income Inequality. Cambridge, MA: Harvard University Press.

García-Peñalosa, C. (2010) 'Income distribution, economic growth and European integration'. Journal of Income Inequality, Vol. 8, pp. 277-292.

Goedemé, T. and Collado, D. (2016) 'The EU Convergence Machine at Work: To the Benefit of the EU's Poorest Citizens?'. Journal of Common Market Studies, forthcoming.

Katz. L.F. and K.M. Murphy (1992) 'Changes in relative wages, 1963-1987: supply and demand factors'. Quarterly Journal of Economics, Vol. 107, pp. 35-78.

Krugman, P. (1991): Geography and Trade. MIT Press, Cambridge.

Krugman, P. (1991b) 'Increasing returns and economic geography'. Journal of Political Economy, Vol. 9, pp. 483-499.

Midelfart, H.K., Overman, H.G. and Venables, A.J. (2003) 'Monetary union and the economic geography of Europe'. Journal of Common Market Studies, Vol. 41, pp. 847-868.

Monfort, M., Cuestas, J.C. and Ordóñez, J. (2013) 'Real Convergence in Europe: A Cluster Analysis'. Economic Modellling, Vol. 33, pp. 689-694.

OECD (2008): Growing Unequal? Income Distribution and Poverty in OECD Countries, OECD Publishing, Paris.

OECD (2011): Divided We Stand: Why Inequality Keeps Rising, OECD Publishing, Paris.

OECD (2012): OECD Employment Outlook, OECD Publishing, Paris.

OECD (2015): In It Together: Why Less Inequality Benefits All, OECD Publishing, Paris.

Ordóñez, J., H. Sala and Silva, J.I. (2015) 'Real unit labour costs in Eurozone countries: drivers and clusters'. IZA Journal of European Labor Studies, Vol. 4, pp. 1-19.

Phillips, P. and Sul, D. (2007) 'Transition Modeling and Econometric Convergence Tests'. Econometrica, Vol. 75, pp. 1771-1855.

Phillips, P. and Sul, D. (2009) 'Economic Transition and Growth'. Journal of Applied Econometrics, Vol. 24, pp. 1153-1185.

Solt, F. (2009) 'Standardizing the World Income Inequality Database'. Social Science Quarterly 90, No. 2, pp. 231-242.

Solt, F. (2014) 'The Standardized World Income Inequality Database'. Working Paper SWIID Version 5.0, October 2014.

Wade, R. H. (2004) 'Is globalization reducing poverty and inequality?' World Development, Vol. 32, pp. 567-589. 


\section{Appendix 1. Tables.}

Table A1. Unemployment convergence, all countries (1960-2015)

\begin{tabular}{cccc}
\hline & \multicolumn{3}{c}{ 1st Convergent Club test } \\
\hline & $\beta$ & t-stat. & Countries \\
\hline const & -1.583 & -1.778 & France, Greece, Ireland, Italy, Portugal, and \\
$\log t$ & 0.161 & 0.612 & Spain \\
\hline \multicolumn{4}{c}{ 2nd Convergent Club test } \\
\hline & $\beta$ & t-stat. & Countries \\
\hline $\log t$ & -0.349 & -0.911 & Belgium, Denmark, Germany, Netherlands, \\
\hline
\end{tabular}

Table A2. Unemployment convergence: sub-cluster analysis, first cluster

\begin{tabular}{cccc}
\hline & \multicolumn{3}{c}{ 1st Convergent Club test } \\
\hline & $\beta$ & t-stat. & Countries \\
\hline const & -15.590 & -0.979 & Greece and Spain \\
$\log t$ & 5.535 & 1.095 & Countries \\
\hline \multicolumn{4}{c}{ 2nd Convergent Club test } \\
\hline & $\beta$ & t-stat. & Ireland, Italy, Portugal, and France \\
\hline $\log t$ & 2.724 & -3.865 & \\
\hline
\end{tabular}

Table A3. Unemployment convergence: sub-cluster analysis, second cluster

\begin{tabular}{|c|c|c|c|}
\hline \multicolumn{4}{|c|}{ 1st Convergent Club test } \\
\hline & $\beta$ & t-stat. & Countries \\
\hline const & -4.173 & -4.034 & \multirow{2}{*}{ Belgium, Finland, and Sweden } \\
\hline $\log t$ & 1.023 & 3.522 & \\
\hline \multicolumn{4}{|c|}{ 2nd Convergent Club test } \\
\hline & $\beta$ & t-stat. & Countries \\
\hline const & 3.178 & 0.852 & \multirow{2}{*}{ Denmark, Netherlands, UK, and US } \\
\hline $\log t$ & 0.309 & 0.296 & \\
\hline \multicolumn{4}{|c|}{ 3rd Convergent Club test } \\
\hline & $\beta$ & t-stat. & Countries \\
\hline
\end{tabular}




\begin{tabular}{cccc} 
const & 3.311 & 1.344 & Germany and Norway \\
$\log t$ & -1.079 & -1.565 & \\
\hline
\end{tabular}

Table A4. Inequality convergence, all countries (1973-2012)

\begin{tabular}{cccc} 
& \multicolumn{3}{c}{ 1st Convergent Club test } \\
\hline & $\beta$ & t-stat. & Countries \\
\hline const & -1.563 & -1.400 & Greece, Ireland, Italy, Portugal, Spain, Bulgaria, \\
$\log t$ & 0.341 & 0.934 & Hungary, United Kingdom, and USA \\
\hline \multicolumn{4}{c}{ 2nd Convergent Club test } \\
\hline & $\beta$ & t-stat. & Countries \\
\hline $\log t$ & 0.238 & -5.015 & Belgium, France, Netherlands, Denmark, \\
\hline
\end{tabular}

Table A5. Inequality convergence: sub-cluster analysis, first cluster

\begin{tabular}{|c|c|c|c|}
\hline \multicolumn{4}{|c|}{ 1st Convergent Club test } \\
\hline & $\beta$ & t-stat. & Countries \\
\hline const & -0.846 & -0.700 & \multirow{2}{*}{ United Kingdom and USA } \\
\hline $\log t$ & 0.251 & 0.608 & \\
\hline \multicolumn{4}{|c|}{ 2nd Convergent Club test } \\
\hline & $\beta$ & t-stat. & Countries \\
\hline const & 1.925 & 1.084 & \multirow{2}{*}{ Bulgaria and Hungary } \\
\hline $\log t$ & -0.791 & -1.302 & \\
\hline \multicolumn{4}{|c|}{ 3rd Convergent Club test } \\
\hline & $\beta$ & t-stat. & Countries \\
\hline const & -0.489 & -0.475 & \multirow{2}{*}{ Greece, Ireland, Italy, Portugal, and Spain } \\
\hline $\log t$ & 0.122 & 0.375 & \\
\hline
\end{tabular}

Table A6. Inequality convergence: sub-cluster analysis, second cluster

\begin{tabular}{cccc}
\hline & \multicolumn{3}{c}{ 1st Convergent Club test } \\
\hline & $\beta$ & t-stat. & Countries \\
\hline const & -1.354 & -1.192 & France, Germany, and Finland \\
$\log t$ & 0.070 & 0.180 & Countries \\
\hline \multicolumn{4}{c}{ 2nd Convergent Club test } \\
\hline
\end{tabular}




\begin{tabular}{cccc} 
const & -1.623 & -1.903 & Belgium, Netherlands, Denmark, Norway, and \\
$\log t$ & -0.399 & -1.368 & Sweden \\
\hline
\end{tabular}

Table A7. Absolute redistribution convergence, all countries (1973-2012)

1st Convergent Club test

\begin{tabular}{cccc}
\hline & $\beta$ & t-stat. & Countries \\
\hline const & -4.435 & -7.219 & $\begin{array}{c}\text { Belgium, Denmark, Finland, France, Germany, } \\
\text { Greece, Ireland, Italy, Netherlands, Norway, } \\
\text { Pogtugal, Spain, and Sweden }\end{array}$ \\
& 0.820 & 4.251 & \multicolumn{2}{c}{ 2nd Convergent Club test } \\
\hline & $\beta$ & t-stat. & Countries \\
\hline $\log t$ & -6.106 & -5.981 & United Kingdom and USA \\
\hline
\end{tabular}

Table A8. Absolute redistribution convergence: sub-cluster analysis, first cluster

\begin{tabular}{|c|c|c|c|}
\hline \multicolumn{4}{|c|}{ 1st Convergent Club test } \\
\hline & $\beta$ & t-stat. & Countries \\
\hline const & -0.306 & -0.813 & \multirow{2}{*}{ Denmark, Ireland, and Sweden } \\
\hline $\log t$ & 0.130 & 0.963 & \\
\hline \multicolumn{4}{|c|}{ 2nd Convergent Club test } \\
\hline & $\beta$ & t-stat. & Countries \\
\hline const & -0.351 & -0.518 & Belgium, Finland, France, Germany, \\
\hline $\log t$ & -0.074 & -0.305 & Netherlands, and Norway \\
\hline \multicolumn{4}{|c|}{ 3rd Convergent Club test } \\
\hline & $\beta$ & t-stat. & Countries \\
\hline const & -0.652 & -0.576 & \multirow{2}{*}{ Greece, Italy, Portugal, and Spain } \\
\hline $\log t$ & -0.486 & -1.237 & \\
\hline
\end{tabular}

